\title{
Water Holding Characteristics of Litters from Different Ecological Public Welfare Forest Types
}

\author{
Rui Shi ${ }^{1}$, Biao $\mathrm{Li}^{2}$, Shaoxiong $\mathrm{Liu}^{3}$ and Shu Wang ${ }^{1, *}$ \\ ${ }^{1}$ College of Landscape Architecture, Southwest Forestry University, Kunming, PR China \\ ${ }^{2}$ Key Laboratory of the Ministry of Education for Agro-Biodiversity and Pest Management, Yunnan Agricultural University, \\ Kunming, PR China \\ ${ }^{3}$ Kunming Edible Fungi Institute of All China Federation of Supply and Marketing Cooporatives, Kunming Yunnan, PR China
} *Corresponding author

\begin{abstract}
Water holding characteristics, including, water holding capacity, water holding rate and absorption rate, together with the litter stock from five public welfare forests with different tree composition and identity were measured. The purpose was to understand water-conserving functions of the three plantations. The results showed that litters from five public welfare forests have different characteristics. The great litter production of litter in different ecological public welfare forest types was of Pinus yunnanensis forest, followed by the litter of Alnus nepalensis forest, Cunninghamia lanceolata forest, Eucalyptus globulus forest, and the least amount of litter stock was from Quercus variabilis forest. The total water holding capacity and water holding rate of litter increased logarithmically with increasing immersing time, according with logarithmic equation $W=a^{*} \ln (t)+b$. Water absorption rates of litter in all plantations decreased according to power correlation with increasing time immersed in water, it accord with power equation $W=\mathbf{a}^{*} t^{-\mathrm{b}}(\mathbf{P}<\mathbf{0 . 0 0 1})$.
\end{abstract}

Keywords-ecological public welfare forest; litter; water holding capacity; water holding rate; water absorption rate

\section{INTRODUCTION}

The ecological public welfare forests have multiple functions, including water and soil resource conservation, biodiversity protection, disaster prevention, nutrient and energy balance maintenance [1]. Forest litter has been defined as the organic matters that ultimately returned to the soil surface. Forest litter plays a significant role in promoting the circulation of substances, nutrient balance and maintaining the functions of the forest ecosystem [2-4]. So for, papers of forest litter were about litter decomposition, relation of forest litter and soil nutrient, dynamic model based on forest litter and N, C cycle, effect of forest litter to hydrology, function of forest litter to ecosystem, allelopathic effects of leaf litters, and so on. Litter decomposition rate is strongly affected by nutrient content, water-soluble carbon compound and structural carbon compound in early decomposition period, whereas it is mainly controlled by lignin and cellulose/lignin ratio in later decomposition period. Soil animal can break litter, soil microorganism is an important factor for litter decomposition and human activities also have influence in the litter decomposition [5]. Decomposition rates of forest litter are significantly influenced by climate and fauna along an elevation gradient [6-7], and the climatic variability across an elevation gradient may be the strongest determinant of decomposition dynamics [8]. The most relevant studies have analyzed changes in decomposition rates of native litter types across climatic gradients [7, 9-12]. Fragmentation was shown to be a major process contributing to the stabilization of litters derived $\mathrm{C}$ and $\mathrm{N}$ in soil organic matter [13]. The hydrologic cycle of forest litter was affected by the weight of the litter, the shape of the leaf litter and rainfall intensity [14]. Forest litter layer can absorb water, and increase roughness of the earth's surface so that retard surface runoff, enhance moisture permeability [18]. The porous of litter are larger than soil, so litter can promote water infiltration, delaying time of runoff, lighten erosion degree of runoff, and supply enough water to soil and plants [19]. Some papers show that the capacity of water conservation of litters in different standing forest is diversity [20-24]. This paper investigated litter in five public welfare forest and researched water holding characteristics of litter with the purpose of understanding water conservation function of litters, and this paper can supply scientific proof to development of public welfare forest in Yunnan, China.

\section{THE GENERAL SITUATION OF SAMPLING SITE}

The sampling sites are located in Mengzi county of Yunnan, China, a subtropical climate with temperate and rainy area. The sample plots were karst landform, the soil was acid red soil with thick soil layer, fertile and damp soil. The original vegetation was Alnus nepalensis natural pure forest, Present vegetation landscape showed complex and mosaic distribution patterns with natural secondary forest and planted forest. This study analyzed water holding characteristic of litter in Alnus nepalensis natural pure forest, Pinus yunnanensis planted forest, Cunninghamia lanceolata natural secondary forest, Quercus variabilis natural secondary forest and Eucalyptus globulus planted forest. The stand characteristics of experimental field were shown by table 1 .

TABLE I. THE STAND CHARACTERISTICS OF EXPERIMENTAL FIELD

\begin{tabular}{|c|c|c|c|}
\hline Types of forest & Canopy density & Average height of threes /m & Average diameter at breast height /cm Density /plants $\cdot$ hm $^{-2}$ \\
\hline Alnus nepalensis natural pure forest & 0.91 & 23.42 & 26.18 \\
\hline Pinus yunnanensis planted forest & 0.87 & 18.35 & 20.84 \\
\hline Cunninghamia lanceolata natural secondary forest & 0.85 & 21.05 & 24.69 \\
\hline Quercus variabilis natural secondary forest & 0.76 & 7.44 & 172 \\
\hline Eucalyptus globulus planted forest & 0.92 & 24.91 & 1460 \\
\hline
\end{tabular}




\section{METHOD OF RESEARCH}

The sample area $\left(400 \mathrm{~m}^{2}\right.$ of five different ecological public welfare forests, respectively) was researched in April, 2011, with 3 repetitions. The stockage, water holding capacity, water holding rate and water absorption rate of litters collected from five different public welfare forests were measured experimentally. For each sample area, five quadrat samples of the size of $1 \mathrm{~m} \times 1 \mathrm{~m}$ were used for measurements. Collected fresh litter from five different public welfare forests were weighted, and their litter moisture content were measured. The litter of each quadrat samples was immersed for $0.5,1.0,1.5,2.0,4.0,6.0,8.0,10.0,12.0,16.0$ and 20.0 hours, then those were weighed after picked up and drain for five minutes. The water holding, water holding rate and water absorption rate of litter were calculated according to follow formulas [25-26]:

Water holding capacity $\left(\mathrm{kg} \cdot \mathrm{m}^{-2}\right)=$ Quality of fresh litter $\left(\mathrm{kg} \cdot \mathrm{m}^{-2}\right)$ - Quality of dry litter $\left(\mathrm{kg} \cdot \mathrm{m}^{-2}\right)$

$$
\begin{aligned}
& \text { Water holding rate }(\%)=\frac{\text { Water holding capacity }}{\text { Quality of dry litter }} \times 100 \% \\
& \begin{array}{l}
\text { Water absorption } \\
\frac{\text { Water holding capacity }}{\text { Immersed time }} \times 100 \%
\end{array} \text { rates }\left(\mathrm{g} \cdot \mathrm{kg}^{-1} \cdot \mathrm{h}^{-1}\right)
\end{aligned}
$$

\section{RESULTS AND ANALYSES}

\section{A. Litter Production and Moisture of Litter}

The litter production of litter from five public welfare forests was different, as shown in table 2 . The largest stockage of litter was from Pinus yunnanensis planted forest, which was $2.36 \mathrm{~kg} \cdot \mathrm{m}^{-2}$. One possible reason was that high content of fibre in pine needle so that it is difficult to be digested by microorganism. The second largest stockage of litter was from Alnus nepalensis natural pure forest, $\left(2.06 \mathrm{~kg} \cdot \mathrm{m}^{-2}\right)$, whereas the least stockage of litter was from Quercus variabilis natural secondary forest, $\left(1.63 \mathrm{~kg} \cdot \mathrm{m}^{-2}\right)$. Quercus variabilis are deciduous trees, -and it is likely that the litters from last winter have been digested by microbial action -so that there were few new litters left. Interestingly, Alnus nepalensis are deciduous trees as well, but their litter stock was higher than that of Quercus variabilis, one possible reason was that Alnus nepalensis densities were very high, contributing to high levels of litter input. Because Alnus nepalensis grows on moist slop land and ravine, this might explain why the largest moisture content of litter was found in Alnus nepalensis natural pure forest. By contrast, litters from evergreen coniferous species, Pinus yunnanensis and Cunninghamia lanceolata had small capillary interstice and high moisture-holding capacity, and thus their moisture content

\begin{tabular}{|c|c|c|c|}
\hline Types of forest & Quality of fresh litter $\left(\mathrm{kg} \cdot \mathrm{m}^{-2}\right)$ & Quality of dry litter $\left(\mathrm{kg} \cdot \mathrm{m}^{-2}\right)$ & Moisture content of litter (\%) \\
\hline Alnus nepalensis natural pure forest & 3.68 & 2.06 & 44.02 \\
\hline Pinus yunnanensis planted forest & 2.97 & 2.36 & 20.54 \\
\hline Cunninghamia lanceolata natural secondary forest & 2.65 & 2.00 & 24.53 \\
\hline Quercus variabilis natural secondary forest & 2.01 & 1.63 & 18.91 \\
\hline Eucalyptus globulus planted forest & 2.23 & 1.88 & 15.60 \\
\hline
\end{tabular}
was relatively lower compared to Alnus nepalensis natural pure forest.

TABLE II. THE STOCKAGE OF LITTER IN FIVE DIFFERENT PUBLIC WELFARE FORESTS

B. The Relationship between Water Holding Capacity and Immersed Time

The Fig. 1 shown that the water holding capacity of litters from five public welfare forests were different, revealed water holding capacity of litters were related to quality of litters and immersed time. In same immersed time, the order of water holding capacity of litters was: litters in Alnus nepalensis natural pure forest $>$ litters in Pinus yunnanensis planted forest $>$ litters in Quercus variabilis natural secondary forest $>$ litters in Cunninghamia lanceolata natural secondary forest $>$ Eucalyptus globulus planted forest. The water holding capacity of litters generally increased with increasing immersed time. The water holding capacity increased hastily with immersing process during the a half hour to eight hours, and then increased slowly during eight hours to twelve hours, and rarely changed after being immersed for twelve hours. After immersed for twenty hours, the water holding capacity of litters in Alnus nepalensis natural pure forest, Pinus yunnanensis planted forest, Quercus variabilis natural secondary forest, Cunninghamia lanceolata natural secondary forest and Eucalyptus globulus planted forest were 6.5, 6.1, $5.8,5.6$ and $4.8 \mathrm{~kg} \cdot \mathrm{m}^{-2}$.

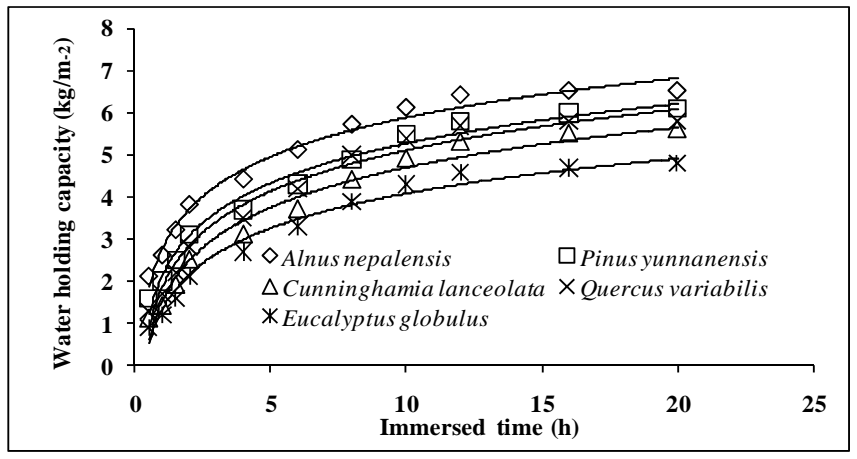

FIGURE I. THE RELATIONSHIP BETWEEN WATER HOLDING CAPACITY AND IMMERSED TIME 
The water holding capacity of litters increased with increasing time immersed in water, according with logarithmic equation $W_{H}=\mathrm{a}^{*} \ln (t)+\mathrm{b}$ (table 3 ). The related coefficient of theoretical water holding capacity of litters base on $W_{H}=\mathrm{a} * \ln (t)+\mathrm{b}$ with the measured water holding capacity were greater than $0.98, \mathrm{P}<0.001$, revealing that water holding capacity was significantly related with immersed time.

TABLE III. THE EQUATION OF WATER HOLDING CAPACITY WITH IMMERSED TIME

\begin{tabular}{|c|c|c|c|}
\hline Types of forest & Equations & Related coefficient & $\mathrm{P}$ \\
\hline Alnus nepalensis natural pure forest & $\mathrm{W}_{H}=1.3338 \ln (t)+2.797$ & 0.9835 & $<0.001$ \\
\hline Pinus yunnanensis planted forest & $\mathrm{W}_{H}=1.3491 \ln (t)+2.1471$ & 0.9876 & $<0.001$ \\
\hline Cunninghamia lanceolata natural secondary forest & $\mathrm{W}_{H}=1.3645 \ln (t)+1.57$ & 0.9901 & $<0.001$ \\
\hline Quercus variabilis natural secondary forest & $\mathrm{W}_{H}=1.4028 \ln (t)+1.8771$ & 0.9842 & $<0.001$ \\
\hline Eucalyptus globulus planted forest & $\mathrm{W}_{H}=1.1961 \ln (t)+1.3364$ & 0.9915 & $<0.001$ \\
\hline
\end{tabular}

\section{The Relationship between Water Holding Rate and Immersed Time}

The water holding rate of litter is a very important aspect of moisture holding capacity, high water holding rate revealed strong moisture holding capacity. The Fig.2 showed that the water holding rates of litters were also related to quality of litters and immersed time. In same immersed time, the order of water holding rate of litters was litters in Alnus nepalensis natural pure forest $>$ litters in Quercus variabilis natural secondary forest $>$ litters in Pinus yunnanensis planted forest>litters in Cunninghamia lanceolata natural secondary forest $>$ Eucalyptus globulus planted forest. The order of water holding rate of litters was different from the order of water holding capacity of litters. Water holding rate of litters from deciduous forest was higher than evergreen forest, evergreen coniferous forest was higher than evergreen broad-leaved forest. The water holding rate of litters increased with increasing immersed time. And the water holding rate and increased hastily with prolonging immersing time during half an hour to ten hours, and increased slowly during ten hours to twelve hours, but hardly changed after twelve hours, it explaining water holding rate of litter verge to saturation after immersed for twelve hours. The water holding rate of litter from Alnus nepalensis, Quercus variabilis, Pinus yunnanensis, Cunninghamia lanceolata and Eucalyptus globules were $315.53 \%$, 355.83\%, 254.79\%, 278.61\% and 255.32\%, revealed Alnus nepalensis and Quercus variabilis can be reproducing tree species of forest for conservation of water supply.



FIGURE II. THE RELATIONSHIP BETWEEN WATER HOLDING RATE AND IMMERSED TIME

The water holding rate of litters increased with increasing time immersed in water, according with logarithmic equation $W_{R}=\mathrm{a} * \ln (t)+\mathrm{b}$, it was shown by table 4 . The related coefficient of theoretical water holding rate of litters base on
$W_{R}=\mathrm{a} * \ln (t)+\mathrm{b}$ with the measured value were greater than 0.97 , $\mathrm{P}<0.001$, revealing that water holding rate was significantly related to immersed time.

TABLE IV. THE EQUATION OF WATER HOLDING RATE WITH IMMERSED TIME

\begin{tabular}{|c|l|l|c|}
\hline Types of forest & \multicolumn{1}{|c|}{ Equations } & Related coefficient & $\mathrm{P}$ \\
\hline Alnus nepalensis natural pure forest & $\mathrm{W}_{R}=64.749 \ln (t)+135.78$ & 0.9842 & $<0.001$ \\
\hline Pinus yunnanensis planted forest & $\mathrm{W}_{R}=56.787 \ln (t)+91.206$ & 0.9788 & $<0.001$ \\
\hline Cunninghamia lanceolata natural secondary forest & $\mathrm{W}_{R}=67.751 \ln (t)+78.013$ & 0.9746 & $<0.001$ \\
\hline Quercus variabilis natural secondary forest & $\mathrm{W}_{R}=86.061 \ln (t)+115.16$ & 0.9762 & $<0.001$ \\
\hline Eucalyptus globulus planted forest & $\mathrm{W}_{R}=63.623 \ln (t)+71.083$ & 0.9771 & $<0.001$ \\
\hline
\end{tabular}




\section{The Relationship between Water Absorption Rate and Immersed Time}

Both Water holding capacity and water holding rate of litter increased with prolonging time of immersing, On the contrary, water absorption rate decreased with prolonging time of immersing as shown by Fig.3. The water absorption rate decreased hastily with prolonging time of immersing among half hour to six hours, but decreased slowly after immersed for six. Therefore, the function of regulating water resources of litter in public welfare forest was most prominent for six hours after rainfall. In same time, the order of water holding rate of litters was litters in Alnus nepalensis natural pure forest $>$ litters in Pinus yunnanensis planted forest $>$ litters in Quercus variabilis natural secondary forest $>$ litters in Cunninghamia lanceolata natural secondary forest > Eucalyptus globulus planted forest. The water absorption rate of litter from Alnus nepalensis, Quercus variabilis, Pinus yunnanensis, Cunninghamia lanceolata and Eucalyptus globules were 4200, 3200, 2600, 2200 and $1800 \mathrm{~g} \cdot \mathrm{kg}^{-1} \cdot \mathrm{h}^{-1}$, revealed water absorption rate of litter in five public welfare forest were different.

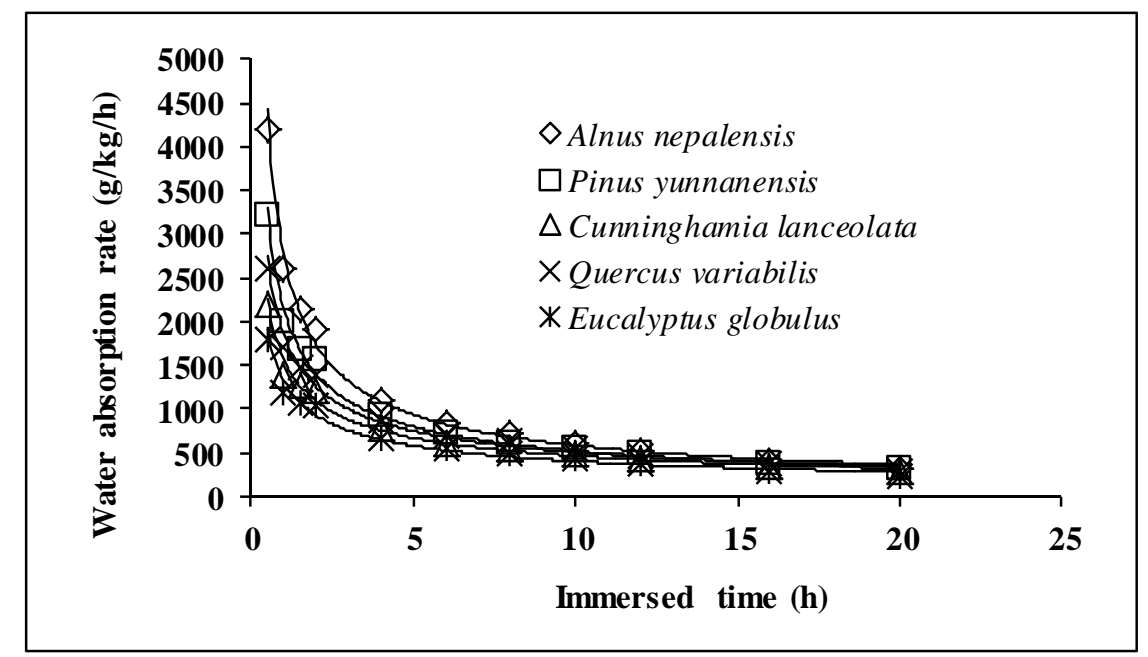

FIGURE III. THE RELATIONSHIP BETWEEN WATER ABSORPTION RATE AND IMMERSED TIME

The water absorption rate of litters decreased with increasing time immersed, it accord with power equation $W_{A}=\mathrm{a} \cdot \mathrm{t}^{\mathrm{b}}$, it was shown by table 5 . The related coefficient of theoretical water absorption rate of litters base on $W_{A}=a \cdot t^{-b}$ with the measured value were greater than $0.98, \mathrm{P}<0.001$, revealed water absorption rate significantly related with immersed time.

TABLE V. THE EQUATION OF WATER HOLDING RATE WITH IMMERSED TIME

\begin{tabular}{|c|c|c|c|}
\hline Types of forest & Equations & Related coefficient & $\mathrm{P}$ \\
\hline Alnus nepalensis natural pure forest & $\mathrm{W}_{A}=2771.1 t^{-0.677}$ & 0.9945 & $<0.001$ \\
\hline Pinus yunnanensis planted forest & $\mathrm{W}_{A}=2151 t^{-0.617}$ & 0.9938 & $<0.001$ \\
\hline Cunninghamia lanceolata natural secondary forest & $\mathrm{W}_{A}=1568.8 t^{-0.53}$ & 0.9861 & $<0.001$ \\
\hline Quercus variabilis natural secondary forest & $\mathrm{W}_{A}=1856.5 t^{-0.566}$ & 0.9855 & $<0.001$ \\
\hline Eucalyptus globulus planted forest & $\mathrm{W}_{A}=1327.9 t^{-0.518}$ & 0.9815 & $<0.001$ \\
\hline
\end{tabular}

\section{CONCLUSION}

(1) The production of litters from five public welfare forests were different, reserves of litters in Pinus yunnanensis planted forest were largest, that were $2.36 \mathrm{~kg} \cdot \mathrm{m}-2$, then were from Alnus nepalensis natural pure forest, Cunninghamia lanceolata natural secondary forest and Eucalyptus globulus planted forest, and Quercus variabilis natural secondary forest were least.

(2) The water moisture content of litters in five public welfare forests were very different, the largest were Alnus nepalensis natural pure forest, and were $44.02 \%$. The second large were evergreen coniferous forest, water moisture content of litters in Pinus yunnanensis planted forest and
Cunninghamia lanceolata natural secondary forest were $20.54 \%$ and $24.53 \%$. Water moisture content of litters in Eucalyptus globulus planted forest and Quercus variabilis natural secondary forest were $18.91 \%$ and $15.60 \%$.

(3) The water holding capacity and water holding rate of litters increasing with immersed time. Water holding capacity and water holding rate increased hastily with prolonging immersing time during half an hour to eight hours, and increased slowly during eight hours to twelve hours, but hardly changed after twelve hours. The water holding rate of broad leaved deciduous forest were largest, the second were evergreen coniferous forest, the least were broad-leaved evergreen forests. 
(4) The relationship of water holding capacity or water holding rate with immersed time were accord with logarithmic equation that was $\mathrm{W}=\mathrm{a}^{*} \ln (\mathrm{t})+\mathrm{b}$, in which $\mathrm{a}$ and $\mathrm{b}$ were constant, the relationship between water absorption rate with immersed time were accord with power equation that was $\mathrm{W}=\mathrm{a}$ *t-b. Those two equations could use to imitate reality change of water holding capacity, water holding rate and water absorption rate of litter in different public welfare forest, this result was similar with previous research results [21, 27].

\section{ACKNOWLEDGEMENTS}

This research was supported by National Natural Science Fund (No. 31460186), Ornamental Plant and Horticulture key disciplines (No. 500017), and key lab of Yunnan Province (No. 000703), Southwest Forestry University; this research was supported by Key Laboratory of Forest Disaster Warming and Control in Yunnan Province Open Fund (No. ZK14A106 and ZK14SB01); Forestry industry research special funds for public welfare projects (No. 201304105); Academic Award for up-and-coming Doctoral Candidate of Yunnan Province (No. kx141156); Key Laboratory of Conservation of Rare, State Forestry Administration Open Fund 2014.

\section{REFERENCES}

[1] W. Z. Li, X. X. Zheng, P. X. Zhao, "Advances in Researches on the Benefit of Non-commercial Forest and Its Evaluation Method”, Journal of Northwest Forestry University, vol. 16, PP. 88-92, 2001 (in Chinese)

[2] B. Lin, Q. Liu, Y. Wu, H. He, “Advances in the studies of forest litter”, Chinese Journal of Ecology, vol. 23, PP. 60-64, 2004

[3] PAN Kaiwen, HE Jing and WU Ning: 'Effect of $f$ orest litter on microenvironment conditions of forestland', Chinese Journal of Apply Ecology, Jan. 2004, 15(1):153 158

[4] H. Fang, J. M. Mo, "Effects of nitrogen deposition on forest litter decomposition”, Acta Ecological Science, vol. 26, PP. 3127-3136, 2006

[5] F. Zeng,, Z. J. Qiu, X. Y. Xu, "Review on forest litter decomposition”, Ecology and Environmental Sciences, vol. 19, PP. 239-243, 2010

[6] P. M. Vitousek, D. R. Turner, W. J. Parton, "litter decomposition on the Mauna Loa environment matrix, Hawaii. I: Patterns, mechanisms, and models”, Ecology, vol. 75, pp. 418-429, 1994:

[7] S. J. Wang, H. H. Ruan, B. Wang, "Effects of soil microbarthropods on plant litter decomposition across an elevation gradient in the Wuyi Mountains”, Soil Biol Biochem, vol. 41, pp. 891-897, 2009

[8] P. E. Lavell, A. Blanchart, S. Martin, A. Martin, F. Spain, I. Toutain, R. Schaefer, "A hierarchical model of decomposition in terrestrial ecosystems: application to soils of the humid tropics”, Biotropica, vol. 25, pp. 130-150, 1993

[9] J. B. De Catanzaro, J. P. Kimmins, "Changes in the weight and nutrient composition of the litter fall in three forest ecosystem types on coastal British Columbia”, Can J Bot, vol. 63, pp. 1046-1056, 1985

[10] J. G. Cepeda-Pizarro, W. G. Whitford, "Decomposition patterns of surface leaf litter of six species along a Chihuahuan Desert watershed”, Am Midl Nat, vol. 123, pp. 319-330, 1989
[11] Y. Steinberger, A. Shmida, W. G. Whitford, "Decomposition along a rainfall gradient in the Judean desert, Israel”, Oecologia, vol. 82, pp. 322-324, 1990

[12] B. Berg, P. E. Jansson, C. Claugherty, "Climate variability and litter decomposition, results from a transect study. Land-scape-ecological impact of climate change”, IOS, Washington DC, pp. 250-269, 1990

[13] J. A. Bird, M. Kleber, M. S. Torn, ${ }^{~}{ }^{13} \mathrm{C}$ and ${ }^{15} \mathrm{~N}$ stabilization dynamics in soil organic matter fractions during needle and fine root decomposition”, Org Geochem, vol. 39, pp. 465 - 477, 2008

[14] Y. Sato, T. Kumagal, A. Kume, "Experimental analysis of moisture dynamics of litter layers the effects of rainfall con 2ditions and leaf shapes”, Hydrol Process, vol. 18, pp. 3007 - 3018, 2008

[15] T. E. Wood, D. Lawrence, "No short-term change in soil properties following four-fold litter addition in a Costa Rican rain forest", Plant and Soil, vol. 307, pp. 113-122, 2008

[16] T. E. Wood, D. Lawrence, D. A. Clark, R. L. Chazdon, "Rain forest nutrient cycling and productivity in response to large-scale litter manipulation”, Ecology, vol. 90, pp.109-121, 2009

[17] R. Ahmed, A. T. M. Hoque, M. K. Hossain, “Allelopathic effects of leaf litters of Eucalyptus camaldulensis on some forest and agricultural crops”, Journal of Forestry Research, vol. 19, pp.19-24, 2008

[18] Y. Q. Peng, L. Xue, H. Cao, X. R. Ren, L. Liang, "Water Holding Characteristics in Three Broadleaved Plantation", Journal of Soil and Water Conservation, vol. 20, pp. 189-200, 2006

[19] M. Putuhenaw, I. Cordery, "Estimation of interception capacity of the forests floor", Journal of Hydrology, vol. 180, pp. 283-299, 1996

[20] Y. W. Zhou, W. H. Huang, H. Y. Chen, L. Xue, Q. H. Xu, R. G. Li , "Water-holding ability of litter and soil in different plantations", Ecology and Environment, vol. 12, pp. 449-451, 2003

[21] X. R. Ren, L. Xue, H. Cao, X. E. Wang, T. F. Xie, "Water Holding Characteristics of Litter in Three Plantation", Journal of South China Agricultural University, vol. 29, pp. 47-51, 2008

[22] B. He, C. B. Huang, J. G. Wei, X. N. Mo, M. B. Wei, Y. Rong, Y. P. Chen, "Reserves and Water Capacity Characteristics of Litter in Taiwania flousiana Plantation at Different Stand Age”, Journal of Northeast Forestry University, vol. 37, pp. 44-46, 2009

[23] Z. Z. Pan, W. H. Yang, Y. P. Qu, "Hydrological Effects of Litters in Different Forest Type”, Journal of Northeast Forestry University, vol, 30, pp. 19-21, 2009

[24] J. Huang, X. M. Zhang, J. C. Zhang, "Comprehensive Evaluation on Soil and Water Conservation Function of Main Forest Types of Ecological Protection Forest in Kaihua County", Research of Soil and Water Conservation, vol. 17, pp. 87-91, 2010

[25] L. Xue, Y. J. He, Q. Ming, W. Min, Y. Xu, "Water Holding Characteristics of Litter in Plantations in South China", Acta Phytoecologica Sinca, vol. 29, pp. 415-421, 2009

[26] L. Xue, L. L. Liang, X. R. Ren, H. Cao, X. E. Wang, T. F. Xie , “Soil Physical Properties and Water Conservation Function of Model Plantations in South China”, Chinese Journal of Soil Science, vol. 9, pp. 986-989, 2008

[27] H. Cao, L. Xue, L. L. Liang, X. R. Ren, T. F. Xie, X. E. Wang, "Water Holding Characteristics in Three Ecological Forests”, Chinese Journal of Soil Science, vol. 40, pp. 34-37, 2009. 